\title{
O método de estudo de caso aplicado no ensino em cursos de pós-graduação em ciências contábeis
} The case study method applied in teaching in post-graduation courses in accounting
sciences

Desarrollo del método estudio de casos en los cursos de posgraduación en ciencias contables

\section{Edvalda Araújo Leal}

Professora Adjunta da Universidade Federal de Uberlândia (UFU)

Doutora em Administração pela Fundação Getúlio Vargas

Endereço: Avenida João Naves de Ávila, 2121 - Bloco F - Sala 1F246

CEP: 38400-902 - Uberlândia/MG - Brasil

E-mail: edvalda@ufu.br

Telefone: (34) 988692748

\section{Rodrigo Lucena de Oliveira}

Bacharel em Ciências Contábeis pela Universidade Federal de Uberlândia (UFU)

Endereço: Avenida dos Ferreiras, 475, Jardim Califórnia.

CEP: 38406-136 - Uberlândia/MG - Brasil

E-mail: rodd.lucena@gmail.com

Telefone: (34) 91987877

Artigo recebido em 16/04/2017. Revisado por pares em 08/03/2018. Reformulado em 06/04/2018. Recomendado para publicação em 15/06/2018 por Carlos Eduardo Facin Lavarda (Editor-Chefe). Publicado em 30/06/2018. 


\section{Resumo}

O objetivo deste trabalho é investigar as habilidades e competências desenvolvidas pela aplicação do método do estudo de caso no processo ensino-aprendizagem dos estudantes de Pós-Graduação em Ciências Contábeis. A amostra conta com 180 discentes, representando 10 estados brasileiros. Para a análise dos dados, utilizou-se a análise fatorial exploratória, tendo sido identificados dois fatores que explicam $62,03 \%$ da variação total dos dados. Tais fatores foram caracterizados por: Habilidades e Competências Adquiridas com a utilização do Método do Estudo de Caso; e Requisitos para Aplicação do Método do Estudo Caso em sala de aula. $\mathrm{Na}$ opinião dos discentes de Pós-Graduação em Ciências Contábeis, o método do estudo de caso contribui para seu aprendizado e auxilia no desenvolvimento de habilidades e competências, tais como: a capacidade de comunicação, o trabalho em equipe e a aptidão para refletir sobre situações reais e teoria estudada em sala de aula, o que auxiliará na análise crítica.

Palavras-chave: Método de ensino; Estudo de caso; Ciências contábeis

\section{Abstract}

The objective of this work is to investigate the skills and competences provided by the application of the case study method in the teaching-learning process of postgraduate students in Accounting Sciences. The sample has 180 students, representing 10 Brazilian states. For the analysis of the data was used the exploratory factorial analysis, two factors were identified that explain $62.03 \%$ of the total data variation. These factors were characterized by skills and competencies acquired with the case study method and requirements to the application of the case study method in the classroom. In the opinion of graduate students in Accounting Sciences, the case study method contributes to their learning and helps in the development of skills and competences, such as: communication skills, teamwork and ability to reflect on real situations and the theory studied, which will aid in the critical analysis.

Keywords: Teaching method; Case study; Accounting sciences

\section{Resumen}

El objetivo de este trabajo es investigar el desarrollo de las habilidades y competencias adquiridas mediante el empleo del método Estudio de Casos durante el proceso de enseñanzaaprendizaje de los cursos de postgraduación en Ciencias Contables. La muestra estuvo compuesta por 180 estudiantes pertenecientes a 10 Estados brasileños. Para el tratamiento de los datos se utilizó el análisis factorial exploratorio, identificando dos factores que explican el $62.03 \%$ de la variación total de los datos. Estos factores fueron caracterizados por las habilidades y competencias asociadas al empleo del método objeto de estudio y los requisitos de su aplicación. Según la opinión de los estudiantes, el referido método, contribuye al perfeccionamiento del proceso de enseñanza-aprendizaje, desarrollando habilidades y competencias para la comunicación, trabajo en equipo y posibilidades de reflexión y análisis crítico sobre situaciones reales con la teoría estudiada.

Palabras clave: Método de enseñanza-aprendizaje; Estudio de casos; Ciencias Contables 


\section{Introdução}

A expansão do ensino superior no Brasil representa um marco no cenário da educação brasileira. Os dados do Instituto Nacional de Estudos e Pesquisas Educacionais Anísio Teixeira (INEP) evidenciam um aumento expressivo na oferta de cursos de graduação nos últimos anos, tendo em vista o aumento de 28.671 cursos, em 2009, para 34.366, em 2016, com um total 8.048.701 alunos matriculados nesse nível de ensino (INEP, 2017). Nesse contexto, o curso de Ciências Contábeis é responsável por, aproximadamente, $4,4 \%$ do total de matrículas nos cursos de graduação no Brasil, ocupando a quinta colocação no ranking dos cursos mais demandados pelos estudantes ingressantes no curso superior (INEP, 2017).

Em relação à pós-graduação stricto sensu no país, ainda que mais modesta se comparada à graduação, também se verifica uma expansão, havendo crescimento do número de matrículas, bem como da abertura de novos programas em todas as áreas de ensino (CAPES, 2016). Na área de Ciências Contábeis, os programas de pós-graduação stricto sensu no Brasil, surgiram na década de 1970. O primeiro programa de mestrado foi criado na Faculdade de Economia, Administração e Contabilidade da Universidade de São Paulo (USP). Em 1978, a USP inicia as atividades de doutorado com a implantação do primeiro Programa de Doutorado em Ciências Contábeis na FEA/USP. Contudo, o crescimento dos cursos de pós-graduação na área contábil ocorreu a partir da década de 1990, uma vez que, ao longo dos anos 1980, não foram implantados novos programas stricto sensu em Ciências Contábeis. Os cursos de Mestrado Acadêmico, Mestrado Profissional e Doutorado em Ciências Contábeis reconhecidos pela Coordenação de Pessoal de Nível Superior (CAPES), até junho/2016, somam 40 cursos, sendo 23 cursos de mestrado, 4 de mestrado profissional e 13 de doutorado (CAPES, 2016).

Face ao exposto, torna-se relevante a busca pela qualidade do ensino em contabilidade, pois vislumbra-se um cenário em que a sociedade requer profissionais qualificados para a atuação nas empresas, o que leva ao aumento das exigências por maior eficiência e eficácia na transmissão do conhecimento na área contábil. Laffin (2002) comenta que as metodologias aplicadas no ensino da contabilidade, em muitos momentos, se restringem à transmissão de conhecimentos contábeis meramente técnicos e mecanicistas. Assim, novas técnicas e métodos aplicados no ensino podem ser providenciais para a melhoria da qualidade do ensino de pósgraduação.

No que concerne aos métodos de ensino aplicados em sala de aula, Bordenave e Pereira (2006) abordam que há um emprego excessivo, quase que exclusivamente, de aulas expositivas que não dão suporte para que ocorra a qualificação exigida atualmente pelas organizações. Assim, percebe-se a necessidade de se diminuir a distância entre a academia e o ambiente organizacional, conforme preconiza o Conselho Nacional de Educação CNE/CES, na Resolução 10/2004, que define as Diretrizes Curriculares para o Curso de Ciências Contábeis de forma a atender às necessidades e demandas dos alunos, do mercado e da sociedade.

A temática de educação contábil tem se tornado foco de alguns estudos (LAFFIN, 2002; ROESCH, 2007a; ARAUJO; SANTANA, 2008; CELERINO; PEREIRA， 2008; VASCONCELOS, CAVALCANTE; MONTE. 2012; ANTONELLI; COLAUTO; CUNHA, 2012), tendo ganhado destaque a necessidade de utilização de novos métodos de ensino aplicados no processo ensino-aprendizagem.

Alguns estudos internacionais foram desenvolvidos para explicar como o método do estudo de caso poderá ser conduzido na sala de aula (KNECHEL, 1992; BRUNER et al., 1999; WEBER; KIRK, 2000; MACY; NEAL, 2002), evidenciando esses trabalhos a relevância do planejamento das aulas e o comportamento do aluno durante a aplicação do método.

Menezes (2009) define que o método do estudo de caso aplicado no ensino se baseia no princípio de que se aprende fazendo. Sendo assim, o referido método visa a desenvolver a 
capacidade do estudante de tomar decisões acertadas e entrar em ação, inserindo-o constantemente em situações em que, como gestor, deverá não somente avaliar os fatos e pesar as opiniões, mas, também, agir com responsabilidade.

Diante do contexto apresentado, o problema que motivou o presente estudo é: Quais as habilidade e competências são evidenciadas com a aplicação do método do estudo de caso no processo ensino-aprendizagem na pós-graduação em Ciências Contábeis? Assim, o objetivo é investigar as habilidades e competências proporcionadas pela aplicação do método do estudo de caso no processo ensino-aprendizagem dos estudantes de Pós-Graduação em Ciências Contábeis.

A justificativa para a pesquisa respalda-se na abordagem proposta por Machado e Callado (2008), os quais afirmam que o método de estudo de caso é capaz de preencher lacunas que outros mecanismos pedagógicos não conseguem com a mesma eficiência. Assim, o referido método torna-se relevante no que concerne ao oferecimento de estratégias de ensino contemporâneas para a educação contábil, principalmente, nos cursos de pós-graduação, propiciando, consequentemente, melhorias na qualidade do ensino e proporcionando o contato com casos reais vivenciados nas organizações. Salienta-se que grande parte dos estudos relacionados ao tema, como os trabalhos de Ikeda, Veludo-de-Oliveira e Campomar (2006), Machado e Calado (2008), De Assis et al. (2013), entre outros, foi desenvolvida para alunos de graduação, não abrangendo os discentes de pós-graduação.

\section{Fundamentação Teórica}

\subsection{Conceitos, Características e Finalidades do Método do Estudo de Caso}

É importante destacar a diferença entre a técnica do estudo de caso para pesquisa acadêmica e o método do estudo de caso para o ensino, também denominado por alguns autores apenas como método do caso, sendo os dois, por vezes, bastante confundidos. O estudo de caso para pesquisa, segundo Gil, Licht e Oliva (2005), começou a ser utilizado na medicina a partir de pesquisas sobre doenças, sendo, posteriormente, popularizado como delineamento de pesquisa social pela Universidade de Chicago e, então, amplamente utilizado em pesquisas de caráter investigativo.

Já o estudo de caso como método de ensino, de acordo com Silva e Castilho (2011), foi desenvolvido na escola de Direito de Harvard, em 1880, por Christopher Langdell, que expunha casos de tribunais para os alunos a fim de unir a teoria com a prática. Assim, enquanto o primeiro tem a finalidade de responder questões particulares por meio da investigação de objetos ou fenômenos específicos e delimitados, o segundo visa à exposição aos alunos de situações complexas para análise e tomada de decisão, A contabilidade é considerada uma ciência social aplicada, tendo sua fundamentação teórica e métodos de ensino e pesquisa como base outras ciências, como a Sociologia e a Psicologia.

Ademais, existem diversas metodologias de ensino usadas em cursos de Ciências Contábeis pelos professores no processo de ensino e aprendizagem nos cursos de pós-graduação e, entre as metodologias ativas, o estudo de caso ou método do caso têm se popularizado diante da necessidade de se propiciar aos alunos a vivência prática para lidar com as complexidades inerentes ao exercício da profissão (AMBROSINI; BOWMAN; COLLIER, 2010). Nota-se então uma grande relevância na aplicação do método do estudo de caso por proporcionar ao estudante a oportunidade para desenvolver habilidades administrativas e gerenciais a partir de um ambiente de laboratório (GIL, 2004).

No Brasil, segundo Roesch (2007b), o uso do método do estudo de caso é recente. Houve, no passado, de acordo com Roesch (2007a), uma tentativa de disseminação do método 
do estudo de caso na década de 1970, por meio da criação de uma Central Brasileira de Casos, com os polos de difusão sendo a Universidade Federal do Rio de Janeiro, a Universidade Federal de Minas Gerais e a Universidade Federal do Rio Grande do Sul. No entanto, essa central funcionou apenas durante a década de 1980, sendo desativada posteriormente.

O Quadro 1 evidencia, de acordo com Gil (2004), as finalidades do uso do método do estudo de casos.

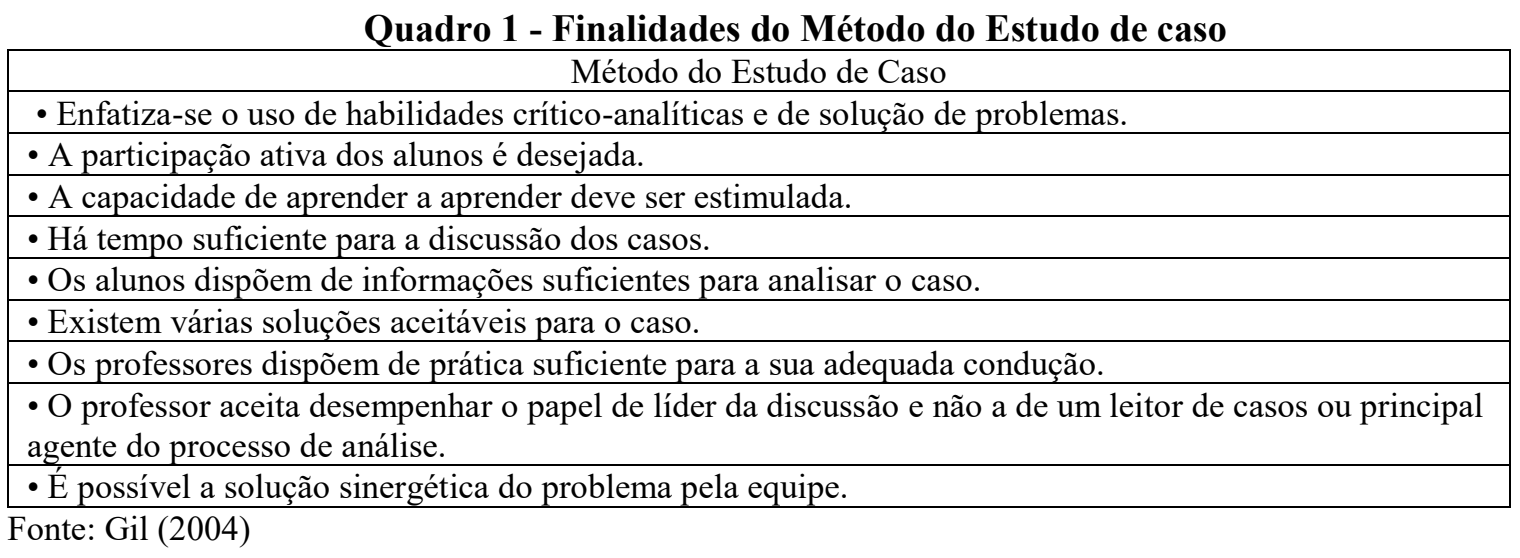

O conceito de estudo de caso voltado ao ensino é resumido por Martins (2006, p. 7) da seguinte forma: "estudo de caso é - técnica de ensino em que o professor (instrutor) explica ensina - determinado conteúdo após os alunos estudarem um caso, geralmente relatando uma situação real já ocorrida". E Graham (2010, p. 38) assevera que "o que o caso faz é dar vida à teoria - e teoria à vida". Esse autor reforça que, diferentemente das aulas tradicionais, em que o conhecimento é de propriedade única do professor e segue, unidirecionalmente, do professor para o estudante, na metodologia de estudos de caso, assume-se que o professor e o aluno contribuem para o processo de aprendizagem.

Aragão e Sango (1995) e De Assis et al. (2013) apontam que há uma grande dificuldade para se encontrarem casos de empresas brasileiras. Lourenço e Magalhães (2014) observaram, em uma pesquisa com 61 docentes de três Instituições de Ensino Superior, que, embora tenham sido encontrados 48 casos para ensino publicados em periódicos e eventos da área de Administração, os docentes pesquisados afirmaram não utilizar tais casos na prática em sala de aula, principalmente, por não terem acesso aos anais dos eventos e periódicos como fontes de busca para os casos. Esse fato evidencia a falta de conhecimento, por parte dos docentes, sobre o que é um caso para ensino, onde localizá-los e como aplicá-los em sala de aula.

Costa e Barroso (1992), conforme pesquisa realizada junto a professores universitários, afirmam que, entre os obstáculos para a produção de casos nacionais, destacam-se o tempo necessário para elaboração de um caso, o alto custo de elaboração, a ausência de remuneração para quem produz o caso e a dificuldade de acesso às informações das empresas. Isso aponta para o fato de que não se desenvolveu no país uma cultura que estimule uma postura de colaboração do empresariado em relação às instituições de ensino e a seus pesquisadores (ABRANTES; MARIANO; MAYER, 2002).

Importante destacar que as fragilidades existentes no acesso e na elaboração de casos para ensino poderão afetar o uso dos mesmos no processo ensino-aprendizagem na área de negócios.

\subsection{O Método do Estudo de Caso no Processo Ensino-Aprendizagem}

Ikeda, Veludo-de-Oliveira e Campomar (2006) descrevem que o método de estudo de caso voltado para o ensino, também conhecido como método do caso, é uma ferramenta baseada 
na exposição de casos verídicos, cuja finalidade é a de fazer com que os alunos estudem, pensem e tomem decisões.

Reafirmando a importância desse método, Hammond (2002) menciona que, embora os conhecimentos obtidos nos livros sejam importantes e valiosos, os ganhos reais de aprendizado vêm da prática ao analisar situações de negócios reais. Vasconcelos et al. (2013) complementam, afirmando que o uso método do estudo de caso para o ensino contribui para que os discentes possam analisar situações-problema reais e, assim, possam discutir sugestões e decisões a serem transportadas para o ambiente empresarial. Da mesma forma, Graham (2010) aborda que esse método tem como objetivo desenvolver a competência e a confiança do aluno quanto ao pensamento crítico e analítico, bem como quanto às habilidades de argumentação e persuasão.

Ademais, a utilização desse método eleva a capacidade analítica e incentiva a busca por diferentes fontes de informação, seja em experiências pessoais ou em conteúdos estudados pelos alunos. Shuell (1986) afirma que, no processo de aprendizagem cognitiva e construtivista, ao qual esse método se aplica, não deve ser levado em conta somente o conhecimento que está sendo adquirido, mas também o conhecimento anterior, pois as experiências acumuladas são igualmente importantes. Essa característica é relevante e corrobora Rees e Porter (2002), os quais acreditam que um dos potenciais benefícios dessa técnica é a possibilidade dos estudantes de compartilharem suas experiências profissionais e pessoais durante o estudo do caso, além de enriquecer a discursão e a análise do grupo.

Importante também apresentar os resultados de estudos que investigaram o uso do método do estudo de caso na educação envolvendo a área de negócios. De Assis et al. (2013) analisaram como casos de fracasso e suas distintas formas de aplicação podem contribuir para uma experiência formativa diferenciada dos alunos. Os autores enfatizaram o estudo de caso como ferramenta pedagógica ao confrontar casos de sucesso, em que as decisões corretas são explicitadas, e casos de fracasso, quando é necessário refletir sobre o problema e propor soluções que não estão explícitas. A conclusão dos alunos foi que esse segundo tipo, casos de fracasso, exige maior dedicação e esforço por parte deles.

Por sua vez, Ikeda, Veludo-de-Oliveira e Campomar (2006) analisaram o emprego do método como recurso pedagógico na área de Administração, frisando a importância da preparação e treinamento para a execução das atividades de docência, entre elas, o domínio de estratégias de ensino e, consequentemente, do método do caso. Em outro estudo, Ikeda, Veludode-Oliveira e Campomar (2007) discutiram o método do caso no ensino na área de Marketing por meio de um levantamento bibliográfico em publicações nacionais e internacionais, tendo sido realizada também uma pesquisa de campo com entrevistas aplicadas a 303 estudantes de graduação e pós-graduação. Os resultados mostraram que os alunos têm atitude positiva em relação à técnica, com preferência para estudos sobre casos brasileiros e reais.

Machado e Calado (2008) elaboraram um ensaio teórico, cujo objetivo foi analisar, na perspectiva da produção do conhecimento, o método do estudo de caso para o ensino da Administração. Os autores apontaram fatores que podem prejudicar o uso desse método, como: (1) a crença de que seu uso pode sanar qualquer problema intrínseco à aprendizagem dos alunos; e (2) a criação de cenários que auxiliam a tomada de decisão pode dar ao aluno a falsa sensação de que a realidade empresarial pode ser enquadrada em algum tipo de modelo. Importante ressaltar que o ambiente empresarial possui variáveis em constante mudança. Assim, conforme os autores, as soluções propostas com o uso desse método deverão estar seriamente associadas à teoria que fundamenta as discussões em sala.

Internacionalmente, Weil et al. (2001) analisaram as percepções de estudantes da África do Sul submetidos aos casos para ensino, os quais alegavam que esse método seria mais eficaz no desenvolvimento de habilidades e competências ao se compararem aos estudantes 
submetidos às técnicas convencionais (seminários, leituras e aulas tradicionais). Os resultados indicaram que o principal benefício percebido pelos alunos, quando do uso de casos para ensino, é a interação em grupo e a possibilidade de aplicação do conhecimento na resolução de problemas práticos (reais), favorecendo a associação da teoria à prática (WEIL et al., 2001).

Gil (2004) constatou que o uso de casos no ambiente acadêmico constitui importante estratégia para o ensino da Administração, pois favorece o alcance de objetivos instrucionais em vários níveis. No entanto, a vida útil de um caso é limitada, e as situações com as quais se deparam os professores são diversas, sendo necessária, então, a elaboração de vários casos para atender à demanda de cursos dessa natureza.

Já Vasconcelos et al. (2013) analisaram, por meio de uma pesquisa bibliográfica, os benefícios potenciais e as limitações relativas à aplicação desse método, constatando os autores que a maior contribuição é o fato de o estudo de caso despertar no aluno o posicionamento crítico e seguro a partir da apresentação do cotidiano empresarial.

Pereira e Leal (2015) investigaram, segundo a percepção dos alunos da disciplina Análise de Custos do curso de Ciências Contábeis de uma universidade federal brasileira, como o método do estudo de caso contribui no processo ensino-aprendizagem. Os autores identificaram que, para os participantes da pesquisa, o método do estudo de caso foi considerado uma ferramenta de ensino eficaz, pois possibilita o exercício da capacidade de refletir sobre situações-problema reais, bem como possibilita a conexão do ensino acadêmico com a realidade profissional, além de agregar valor à aprendizagem, favorecendo a transferência de conhecimento, tanto entre alunos como entre professor e aluno.

Algumas limitações do uso desse método merecem ser destacadas, como De Assis et al. (2013), Ikeda et al. (2005) e Aragão e Sango (1995) apontam: a dificuldade para encontrar casos de empresas brasileiras; e a inquestionável falta de casos locais que abordem problemas de empresas brasileiras ou de empresas estrangeiras no Brasil.

Para autores como Piletti (2004) e Silva e Benegas (2010), as limitações do método do caso podem ainda ser oriundas de problemas operacionais dentro da sala de aula, como a alta quantidade de alunos por sala, média de idade, falta de embasamento técnico por parte do aluno, comprometimento e aceitação dos estudantes e estrutura física disponível para as aulas, o que faz com que o docente precise planejar a aplicação da atividade com antecedência.

Importante ressaltar que a literatura pesquisada apresenta benefícios referentes à utilização do método do estudo de caso para o processo ensino-aprendizagem, mas também apontam fragilidades do método. As pesquisas identificadas não evidenciaram a aplicação do método do estudo de caso com estudantes de pós-graduação, como propõe este estudo. $\mathrm{Na}$ próxima sessão, apresentam-se os procedimentos metodológicos adotados para esta pesquisa.

\section{Metodologia}

Esta pesquisa buscou investigar as habilidades e competências proporcionadas pela aplicação do método do estudo de caso no processo ensino-aprendizagem dos estudantes de Pós-Graduação em Ciências Contábeis.

Para atingir esse objetivo, realizou-se uma pesquisa descritiva que "expõe características de determinada população ou de determinado fenômeno. Pode também estabelecer correlações entre variáveis e definir sua natureza" (VERGARA, 2004, p. 47).

Já a abordagem adotada para a pesquisa foi quantitativa, ou seja, foram empregadas técnicas estatísticas no tratamento dos dados obtidos para uma posterior determinação dos resultados (RICHARDSON, 1999). 


\subsection{Procedimentos para Coleta e Tratamento dos Dados}

Segundo Gil (1999), uma das características mais significativas de uma pesquisa descritiva é a utilização de técnicas padronizadas de coleta de dados. Sendo assim, a presente pesquisa utilizou, para a coleta de dados, a aplicação de um questionário aos alunos pósgraduandos em Ciências Contábeis.

O instrumento de pesquisa (questionário) utilizado foi desenvolvido por Pereira e Leal (2015) em uma pesquisa correlata aplicada aos alunos matriculados na disciplina de análise de custo do curso de graduação em Ciências Contábeis de uma universidade federal brasileira, tendo sido o questionário complementado pela literatura pesquisada.

O questionário apresentou duas partes aos respondentes: a primeira continha questões que solicitam informações para identificar características dos participantes já a segunda parte objetivou avaliar, por meio da apresentação de assertivas, a percepção dos alunos quanto ao uso do método do estudo de caso para fins de ensino-aprendizagem nos cursos de Pós-Graduação em Ciências Contábeis, devendo ser atribuída uma nota de zero a dez para apontar a concordância ou discordância com relação à assertiva apresentada.

Baseando-se no procedimento utilizado por Pereira e Leal (2015), o questionário aplicado aos alunos foi composto de 24 assertivas, cujas respostas foram usadas para compor o banco de dados da etapa descritiva. As assertivas foram divididas em 5 dimensões, como pode ser observado no Quadro 2.

Quadro 2 - Dimensões e número de questões analisadas

\begin{tabular}{|l|c|}
\hline \multicolumn{1}{|c|}{ Dimensões } & $\mathrm{N}^{\text {o }}$ de Questões \\
\hline A influência do método do estudo de caso nas capacidades dos alunos. & 03 \\
\hline A utilização do estudo de caso em sala de aula. & 08 \\
\hline A preferência dos alunos em relação aos tipos de casos. & 07 \\
\hline A aprendizagem por meio de casos. & 03 \\
\hline As dificuldades para aprender por meio de casos. & 03 \\
\hline
\end{tabular}

Fonte: Pereira e Leal (2015)

Importante ressaltar que, antes da aplicação do questionário aos alunos, realizou-se um pré-teste com oito alunos matriculados no curso de Pós-Graduação em Ciências Contábeis de uma IES que abrigava a população do estudo. O objetivo foi verificar a compreensibilidade do instrumento, tendo sido acatadas as sugestões recebidas dos respondentes.

Para a coleta de dados, o questionário foi disponibilizado na plataforma eletrônica do Google, por meio da ferramenta Google Forms, que é um serviço que permite a criação de questionários e o envio ao público-alvo de forma organizada e simples. Os alunos receberam o convite para participação da pesquisa pelos seus correios eletrônicos pessoais e, após dadas as respostas, o questionário preenchido foi devolvido ao criador do documento, permitindo o controle seguro das respostas, a obtenção de feedback diário e a avaliação da necessidade de repetir o envio ou reforçar o pedido de participação.

Para que a pesquisa atingisse o maior número possível de participantes, fez-se contato telefônico e via email com as coordenações dos PPGCCs, solicitando os e-mails dos discentes das turmas para colaboração na pesquisa. Assim, os alunos receberam um e-mail convite, apresentando o objetivo da pesquisa e o endereço eletrônico do formulário, bem como solicitando sua participação.

Para rodar os testes estatísticos, utilizou-se o software Statistical Package for the Social Sciences (SPSS). Primeiramente, realizaram-se as análises descritivas dos dados para a caracterização dos respondentes e, também, para verificar a preferência dos alunos quanto aos estudos de casos utilizados em sala de aula. 
Para a segunda etapa, utilizou-se a análise fatorial exploratória, com o propósito de sintetizar as diversas variáveis propostas no instrumento de pesquisa por meio da identificação de fatores comuns entre elas (FÁVERO et al., 2009, p. 236). Para a análise exploratória, foram testadas 16 assertivas que requeriam dos respondentes opiniões sobre habilidades, competências e fatores que motivam o uso do estudo de caso.

Para a aplicação da análise fatorial exploratória, foram analisados os pressupostos indicados, os quais serão descritos na análise dos resultados.

\subsection{População e Amostra do Estudo}

A população considerada para esta pesquisa consiste em todos os alunos matriculados nos PPGCCs no Brasil no período da coleta de dados deste estudo, que ocorreu de 1 de fevereiro a 30 de abril de 2016, abrangendo os cursos de Mestrado e Doutorado da área de Ciências Contábeis, conforme descrito no Quadro 3. Os PPGCCs selecionados para este estudo foram identificados por meio da Plataforma Sucupira, disponibilizada pela CAPES, totalizando 1.006 discentes matriculados. Salienta-se que 2 instituições (UFSC e FUCAPE) optaram por não participar desta pesquisa.

Quadro 3 - Programas de Pós-Graduação stricto sensu em Ciências Contábeis no Brasil

\begin{tabular}{|c|c|c|c|}
\hline N. & $\begin{array}{c}\begin{array}{c}\text { Instituições de ensino } \\
\text { superior }\end{array} \\
\end{array}$ & Unidade da Federação & Programa \\
\hline 1 & FUCAPE & ES & $\mathrm{M} / \mathrm{D} / \mathrm{MP}$ \\
\hline 2 & FURB & $\mathrm{SC}$ & $\mathrm{M} / \mathrm{D}$ \\
\hline 3 & PUC/SP & SP & $\mathrm{M}$ \\
\hline 4 & UEM & PR & $\mathrm{M}$ \\
\hline 5 & UERJ & $\mathrm{RJ}$ & $\mathrm{M}$ \\
\hline 6 & UFBA & $\mathrm{BA}$ & $\mathrm{M}$ \\
\hline 7 & UFC & $\mathrm{CE}$ & $\mathrm{M} / \mathrm{MP}$ \\
\hline 8 & UFES & ES & $\mathrm{M}$ \\
\hline 9 & UFMG & MG & $\mathrm{M}$ \\
\hline 10 & UFPE & $\mathrm{PE}$ & $\mathrm{M}$ \\
\hline 11 & UFPR & PR & $\mathrm{M} / \mathrm{D}$ \\
\hline 12 & UFRJ & $\mathrm{RJ}$ & $\mathrm{M} / \mathrm{D}$ \\
\hline 13 & UFSC & $\mathrm{SC}$ & $\mathrm{M} / \mathrm{D}$ \\
\hline 14 & UFU & $\mathrm{MG}$ & $\mathrm{M} / \mathrm{D}$ \\
\hline 15 & UNB & $\mathrm{DF}$ & $\mathrm{M} / \mathrm{D}$ \\
\hline 16 & UNIFECAP & SP & $\mathrm{M}$ \\
\hline 17 & UNISINOS & $\mathrm{RS}$ & $\mathrm{M} / \mathrm{D}$ \\
\hline 18 & UPM & SP & MP \\
\hline 19 & USP & SP & $\mathrm{M} / \mathrm{D}$ \\
\hline 20 & USP/RP & SP & $\mathrm{M} / \mathrm{D}$ \\
\hline 21 & UFPB & PB & $\mathrm{M}$ \\
\hline 22 & UFRN & $\mathrm{RN}$ & $\mathrm{M}$ \\
\hline 23 & UNOCHAPECÓ & $\mathrm{SC}$ & $\mathrm{M}$ \\
\hline 24 & UFRPE & $\mathrm{PE}$ & $\mathrm{M}$ \\
\hline
\end{tabular}

Fonte: CAPES (2016)

Legenda: M - Mestrado Acadêmico | M/D - Mestrado Acadêmico/Doutorado | MP - Mestrado Profissional

Por meio de pesquisa, verificou-se que vinte e quatro instituições de ensino oferecem cursos de pós-graduação na área contábil, sendo vinte e três programas de mestrado acadêmico, três oferecem o mestrado profissional e dez programas ofertam o doutorado.

Para a aplicação dos questionários, a amostra foi classificada como aleatória simples, visto que "todos os elementos da população têm igual probabilidade de compor a amostra, e a 
seleção de um particular indivíduo, ou objeto, não afeta a possibilidade de qualquer outro elemento ser escolhido" (MARTINS; THEÓPHILO, 2007, p. 104).

Conforme mencionado anteriormente, a população do estudo corresponde a 1.006 alunos matriculados nos PPGCCs. Esses dados foram confirmados por meio de contato por telefone com as secretarias dos PPGCCs, reforçando que apenas duas IES (UFSC e FUCAPE) não participaram desta pesquisa.

A amostra deste estudo é composta por 180 alunos que se prontificaram a responder à pesquisa e afirmaram ter tido contado com o método do estudo de caso no processo ensinoaprendizagem na pós-graduação. A Tabela 1 apresenta a distribuição dos participantes por estado no qual o PPGCCs está localizado.

Tabela 1 - Distribuição dos participantes por unidade da federação

\begin{tabular}{l|r|r}
\multicolumn{1}{c|}{ Estado } & N & \multicolumn{1}{c}{$\%$} \\
\hline Bahia & 12 & 6,7 \\
\hline Ceará & 3 & 1,7 \\
\hline Distrito Federal & 10 & 5,6 \\
\hline Espirito Santo & 6 & 3,3 \\
\hline Minas Gerais & 21 & 11,7 \\
\hline Paraná & 23 & 12,8 \\
\hline Rio de Janeiro & 12 & 6,7 \\
\hline Rio Grande do Norte & 4 & 2,2 \\
\hline Rio Grande do Sul & 32 & 17,8 \\
\hline Santa Catarina & 17 & 9,4 \\
\hline São Paulo & 40 & 22,2 \\
\hline Total & 180 & 100,0 \\
\hline
\end{tabular}

Fonte: Dados da Pesquisa

A partir da Tabela 1, é possível verificar que houve a participação de alunos vinculados a programas de 10 estados, o que pulveriza a representação de estudantes de PPGCCs no Brasil.

\section{Análise e Discussão dos Resultados}

\subsection{Análise descritiva}

Os dados coletados na primeira parte do questionário permitiram a utilização de técnicas para descrever e sumarizar informações acerca do perfil dos participantes da pesquisa. A Tabela 2 evidencia a caracterização dos respondentes.

Observa-se que, do total de respondentes, $53,89 \%$ são homens, $31,7 \%$ têm idade entre 31 e 40 anos, a grande maioria dos participantes está cursando programas de mestrado (78,3\%), 53,7 \% estão trabalhando e 67,78 \% afirmaram já terem atuado no ensino. Embora esta pesquisa tenha como amostra os discentes que afirmaram terem tido experiência com o método do estudo de caso durante as aulas na pós-graduação em Ciências Contábeis, foi perguntando, de forma complementar, àqueles discentes que já atuaram na docência se eles, em algum momento, aplicaram o método do estudo de caso em suas aulas. Constatou-se que pouco mais da metade dos respondentes $(54,44 \%)$ declarou já ter tido experiência com a aplicação do método na condição de docente. Importante ressaltar que 53\% dos alunos da Pós-Graduação em Contabilidade estão trabalhando, ou seja, estão conciliando a dedicação ao curso com a atuação no mercado. 
Tabela 2 - Características descritiva da amostra

\begin{tabular}{|c|c|c|c|}
\hline \multicolumn{4}{|c|}{ Gênero } \\
\hline Feminino & $46,11 \%$ & Masculino & $53,89 \%$ \\
\hline \multicolumn{4}{|c|}{ Idade } \\
\hline Até 25 anos & $14,44 \%$ & De 31 a 40 anos & $31,67 \%$ \\
\hline De 26 a 30 anos & $29,44 \%$ & De 41 a 50 anos & $17,78 \%$ \\
\hline Acima de 50 anos & $6,67 \%$ & & \\
\hline \multicolumn{4}{|c|}{ Modalidade } \\
\hline Mestrado & $78,33 \%$ & Doutorado & $21,70 \%$ \\
\hline \multicolumn{4}{|c|}{ Trabalha } \\
\hline Sim & $53,70 \%$ & Não & $46,30 \%$ \\
\hline \multicolumn{4}{|c|}{ Já atuou na docência } \\
\hline Sim & $67,78 \%$ & Não & $32,22 \%$ \\
\hline \multicolumn{4}{|c|}{ Ofereceu aulas com Estudo de Caso } \\
\hline Sim & $54,44 \%$ & Não & $45,56 \%$ \\
\hline
\end{tabular}

Fonte: Dados da Pesquisa

Algumas assertivas do questionário objetivaram avaliar, segundo a percepção dos alunos, as preferências pelos tipos de estudo de caso utilizados como estratégia de ensino nos programas de pós-graduação. Para mensurar o comportamento das respostas, foram utilizadas as medidas convencionais de estatística descritiva, conforme apresentado na Tabela 3.

Tabela 3 - Percepção dos discentes sobre o uso do estudo de caso

\begin{tabular}{l|r|r|r}
\multicolumn{1}{c|}{ Preferências para o Uso do Método do estudo de Caso } & Média & Mediana & \multicolumn{1}{c}{$\begin{array}{l}\text { Desvio } \\
\text { Padrão }\end{array}$} \\
\hline $\begin{array}{l}\text { 12. Gosto de casos de fracasso, onde se faz necessário refletir sobre } \\
\text { o problema e propor soluções. }\end{array}$ & 7,516 & 8,00 & 2,164 \\
\hline 13. Gosto de casos com bastantes informações e detalhes. & 7,527 & 8,00 & 2,157 \\
\hline $\begin{array}{l}\text { 14. Prefiro casos reais, brasileiros, recentes e que abordem situações } \\
\text { cotidianas de uma empresa. }\end{array}$ & 7,694 & 8,00 & 2,140 \\
\hline $\begin{array}{l}\text { 15. Gosto de casos de sucesso, onde as decisões corretas são } \\
\text { explicitadas. }\end{array}$ & 6,988 & 7,00 & 2,257 \\
\hline $\begin{array}{l}\text { 16. Gosto quando há diálogos no texto do caso. } \\
\text { 17. Gosto de casos que envolvam a interdisciplinaridade entre as } \\
\text { várias disciplinas do curso. }\end{array}$ & 8,133 & 9,00 & 2,034 \\
\hline $\begin{array}{l}\text { 18. Gostaria que os casos fossem usados com outras ferramentas } \\
\text { pedagógicas. }\end{array}$ & 7,833 & 8,00 & 1,976 \\
\hline
\end{tabular}

Fonte: Dados da Pesquisa

Nota-se que, para as assertivas apresentadas, os participantes demonstraram um alto nível de concordância, sendo as maiores médias correspondentes às assertivas 17 e 18, com 8,133 e 7,833, respectivamente, indicando que os estudantes de pós-graduação têm preferências por estudos de casos interdisciplinares e que esses sejam utilizados juntamente com outras ferramentas pedagógicas. De qualquer forma, as médias das notas atribuídas às demais assertivas relacionadas aos tipos de casos também ficaram acima de 7,0, ou seja, os pósgraduandos preferem casos detalhados, casos de sucesso e/ou fracasso e casos reais, brasileiros e atuais. Importante ressaltar que os pós-graduandos em contabilidade preferem casos de fracasso $(7,516)$ do que casos de sucesso $(6,988)$, resultados que convergem para a pesquisa realizada por Ikeda, Veludo-de-Oliveira e Campomar (2007) na área de Marketing. 
Importante destacar que os discentes da pós-graduação têm interesse no método do estudo de caso, mas a literatura indica a escassez de casos envolvendo as empresas brasileiras (ARAGÃO; SANGO, 1995; DE ASSIS et al., 2013). Além disso, vários docentes afirmam não utilizar os estudos de casos por não terem acesso a eles (LOURENÇO; MAGALHÃES, 2014)

Além das assertivas apresentadas na Tabela 3, perguntou-se aos participantes a opinião sobre a preparação dos estudantes de pós-graduação para aprender com a utilização de casos, tendo sido identificada uma mediana de 8,5, o que indica que os estudantes estão preparados para tal situação, ou seja, o resultado evidenciou que a maioria se considera apta para aprender por meio da utilização do método no curso.

\subsection{Análise Fatorial Exploratória}

Segundo Fávero et al. (2009), para a aplicação da análise fatorial, é importante que, primeiramente, se examine a matriz de correlação das variáveis para verificar a existência de valores significativos que justifiquem a utilização dessa técnica. Assim, foi necessário avaliar os valores das correlações entre as variáveis, ou seja, o quanto uma delas, de alguma maneira, está relacionada com as outras. Para essa avaliação, foi aplicado o teste KMO (Kaiser-MeyerOlkin) e Bartlett. Conforme afirmam Fávero et al. (2009), o teste KMO confronta as correlações simples com as parciais observadas nas amostras e, ao indicar os valores próximos de 1, mostra que os coeficientes de correlações parciais são baixos, podendo, assim, ser realizada a análise fatorial de forma eficaz. O valor obtido no teste KMO realizado para esta pesquisa foi de 0,923 , o que indicado que o teste é apropriado para a amostra em estudo.

Verificou-se, posteriormente, se as variáveis da pesquisa estão ou não correlacionadas na amostra. Para tanto, aplicou-se o teste de esfericidade de Bartlett que, segundo Fávero et al. (2009), indica que, se a hipótese nula apresentada no teste for rejeitada, há indícios de correlação significativa entre as variáveis originais. O teste de esfericidade de Bartlett apresentou significância, indicando também a possibilidade de aplicação da análise fatorial.

Para simplificar a interpretação dos fatores, é importante realizar uma rotação ortogonal, isto é, girar os eixos nos quais os dados estão armazenados para fornecer uma perspectiva diferente e obter um padrão de fator de carregamento mais simples e mais fácil de interpretar que o original. O método rotação utilizado nesta pesquisa foi o Varimax com a finalidade de minimizar as variáveis que apresentam maiores cargas de fator para cada agrupamento. A Tabela 4 apresenta os resultados evidenciados pela rotação Varimax.

Verifica-se que as variáveis com altas cargas em um determinado fator foram agrupadas, identificando-se dois fatores que explicam $62,03 \%$ da variação total dos dados. Além disso, observa-se que todos os itens obtiveram cargas fatoriais superiores a 0,5 , em total conformidade com o que recomenda Hair et al. (2005).

Para assegurar a confiabilidade dos dados do questionário aplicado, utilizou-se o teste denominado Alpha de Cronbach para medir a consistência interna, visto que esse teste examina a correlação entre as respostas dadas pelos discentes da pesquisa. Em outras palavras, esse índice validou a correlação entre respostas em um questionário por meio da análise de todas as respostas dadas pelos participantes da pesquisa. Os valores obtidos no cálculo do Alpha de Cronbach foram de 0,933 e 0,795 para os fatores 1 e 2, respectivamente. Esses valores são superiores ao valor mínimo de 0,70 exigido por Hair et al. (2005), evidenciando a confiabilidade interna dos dados. 
Tabela 4 - Análise Fatorial (Rotação Varimax)

\begin{tabular}{|c|c|c|}
\hline \multirow{2}{*}{ Itens/ Indicadores } & \multicolumn{2}{|c|}{ Fatores ou Dimensões } \\
\hline & Fator 1 & Fator 2 \\
\hline 1.Estudando por meio de casos melhorou minha capacidade gerencial. & 0,853 & \\
\hline $\begin{array}{l}\text { 2.A discussão de casos em aula melhorou minha argumentação e capacidade } \\
\text { analítica. }\end{array}$ & 0,874 & \\
\hline 3.Estudando por meio de casos melhorou minha capacidade de comunicação. & 0,815 & \\
\hline $\begin{array}{l}\text { 4.O caso trabalhado em sala de aula possibilita a transferência de conhecimento } \\
\text { entre os alunos. }\end{array}$ & 0,768 & \\
\hline $\begin{array}{l}\text { 6.A aplicação do método do estudo de caso em sala de aula estimula o trabalho } \\
\text { em equipe. }\end{array}$ & 0,661 & \\
\hline $\begin{array}{l}\text { 8.A discussão de casos com meus colegas de classe agrega valor à minha } \\
\text { aprendizagem. }\end{array}$ & 0,708 & \\
\hline $\begin{array}{l}\text { 19.Os casos práticos e reais exercitam minha capacidade de refletir sobre } \\
\text { situações-problema reais. }\end{array}$ & 0,663 & \\
\hline $\begin{array}{l}20.0 \text { método de aprendizagem por meio de casos conecta o ensino acadêmico } \\
\text { com a realidade profissional. }\end{array}$ & 0,729 & \\
\hline 21.É fácil fazer a ligação do caso com as teorias e conceitos. & 0,695 & \\
\hline $\begin{array}{l}\text { 5.Tenho mais motivação para discutir o caso em sala de aula quando me } \\
\text { preparo antes. }\end{array}$ & & 0,525 \\
\hline 7.É preciso preparo do professor para uma aula com discussão de casos. & & 0,581 \\
\hline 9.É preciso a interação do grupo para a resolução do caso. & & 0,533 \\
\hline 10.Uma aula com discussão de casos é mais dinâmica. & & 0,551 \\
\hline 11.É preciso preparo do aluno para uma aula com discussão de casos. & & 0,621 \\
\hline 22.Uma sala com muitos alunos dificulta o ensino por meio de casos. & & 0,662 \\
\hline 23.A falta de embasamento teórico do aluno impossibilita a discussão do caso. & & 0,631 \\
\hline Autovalores (Eigenvalue) & 8,345 & 1,581 \\
\hline \% Variância Explicada & 52,154 & 9,883 \\
\hline \% Variância Acumulada & 52,154 & 62,038 \\
\hline Alfa de Crombach & 0,9335 & 0,7953 \\
\hline
\end{tabular}

Fonte: Dados de Pesquisa

O Fator 1 foi nomeado por "Habilidades e Competências Adquiridas com o Método do Estudo de Caso". Nesse fator, encontram-se as variáveis que, do ponto de vista do participante, evidenciam o enriquecimento de seu aprendizado ou contribuem com o aprendizado coletivo, agregando capacidades analíticas e críticas. Esse fator obteve um índice de variância explicada de $52,15 \%$. Importante ressaltar que os participantes consideram que as principais habilidades e competências propiciadas com a aplicação do método do estudo de caso são: estimular o trabalho em equipe, proporcionar a discussão de problemas reais das empresas e aperfeiçoar a capacidade de comunicação. Para Graham (2010), o método do estudo de caso desenvolve habilidades, como a de trabalho em grupo, de comunicação, de resolução de problemas, bem como extrai lições relevantes para fins de ensino. Da mesma forma, Machado e Callado (2008) afirmam que esse método contribui para a construção de novos conhecimentos para o aluno, seja por meio de associações ou comparações críticas ou por meio da reflexão sobre os resultados alcançados.

Pereira e Leal (2015), em pesquisa realizada com os alunos da graduação em Ciências Contábeis, da disciplina Análise de Custos, também identificaram 'habilidades e competências alcançadas pelo método', ou seja, o fator evidenciou tais características nos estudantes de graduação, indicando a relevância do método.

$\mathrm{Na}$ África do Sul, os estudantes percebem que o principal benefício quando do uso de casos para ensino é a interação em grupo e a possibilidade de aplicação do conhecimento na 
resolução de problemas práticos (reais), favorecendo a associação da teoria e prática (WEIL et al., 2001).

Já o Fator 2 foi caracterizado como "Requisitos para Aplicação do Método do Estudo Caso em Sala de Aula", o qual agrupou as variáveis que estão relacionadas à aplicação dessa metodologia como ferramenta no processo ensino-aprendizagem dos alunos de pós-graduação. As cargas fatoriais verificadas, embora menores que aquelas obtidas no Fator 1, demonstram um grau de concordância dos alunos bastante satisfatório em relação às proposições colocadas, as quais evidenciam características encontradas durante a aplicação do método em sala, sendo 9,88\% seu percentual de explicação. De acordo com Piletti (2004), variáveis como estrutura física disponível, tipo do aluno e conhecimento prévio do conteúdo abordado no estudo de caso têm impacto nos resultados alcançados com a aplicação do método. De Assis et al. (2013) complementam que é importante que o professor averigue os conhecimentos prévios dos alunos, a fim de evitar um conflito cognitivo para que esse possa avançar em sua aprendizagem.

Importante ressaltar as limitações indicadas pelos autores Piletti (2004) e Silva e Benegas (2010) quanto às fragilidades referentes ao comprometimento e aceitação dos estudantes quanto à utilização do método do estudo de caso, bem como quanto à estrutura física disponível para a aula, o que faz com que o docente precise planejar a aplicação da atividade com antecedência.

\section{Considerações Finais}

Este estudo objetivou investigar as habilidades e competências proporcionadas pela aplicação do método do estudo de caso no processo ensino-aprendizagem dos estudantes de Pós-Graduação em Ciências Contábeis. Conforme mencionado na metodologia, foram analisadas as seguintes dimensões: 'a influência do método do estudo de caso nas capacidades dos alunos'; 'a utilização do estudo de caso em sala de aula'; 'a preferência dos alunos em relação aos tipos de casos'; 'a aprendizagem por meio de casos'; e 'as dificuldades para aprender por meio de casos'.

Verificou-se que mais da metade dos respondentes $(54,44 \%)$ declararam já ter tido experiência em sala de aula, como docente, com a aplicação do método do estudo de caso. Os mesmos indicaram a preferência por estudos de casos interdisciplinares e que esses sejam utilizados em conjunto com outras ferramentas pedagógicas.

Por meio da análise fatorial exploratória aplicada no estudo, foram identificados dois fatores, os quais explicam $62,03 \%$ da variação total dos dados. O Fator 1, denominado "Habilidades e Competências Adquiridas com o Método do Estudo de Caso", é composto de variáveis que, do ponto de vista do participante, evidenciam o enriquecimento de seu aprendizado ou do aprendizado coletivo, agregando capacidades analíticas. Já o Fator 2, denominado "Requisitos para Aplicação do Método do Estudo Caso em Sala de Aula", agrupou assertivas relacionadas à aplicação dessa metodologia como ferramenta no processo ensinoaprendizagem dos alunos de pós-graduação.

Os resultados evidenciados no presente trabalho convergiram para os achados da pesquisa realizada por Ikeda, Veludo-de-Oliveira e Campomar (2006), que entrevistaram graduandos em Administração, mestrandos e doutorandos em Administração/Marketing e pósgraduandos de MBA (lato sensu) em Marketing. Os autores constataram uma preferência dos alunos por casos reais, que abordem situações de uma empresa e situações recentes, contemporâneos, da mesma forma que grande parte dos respondentes deste estudo.

Outro estudo que apresentou resultados correlatos foi o De Assis et al. (2013), o qual apontou que fatores como a disciplina em que é o método é aplicado, o professor, o conhecimento ou o prévio contato dos principais conceitos teóricos sobre o tema abordado, 
entre outros, são importantes para o sucesso desse método de ensino. O Fator 2 deste estudo demonstra o mesmo ponto de vista dos discentes de pós-graduação.

O presente estudo contribuiu para a constatação de que a prática docente na pósgraduação na área contábil deve se expandir para além das estratégias e técnicas tradicionais aplicadas no ensino. Percebe-se que os discentes demandam inovações e técnicas aprimoradas que promovam alternativas para o processo decisorial das organizações. Os resultados deste estudo evidenciaram ainda que, na opinião dos discentes de Pós-Graduação em Ciências Contábeis, o método do estudo de caso contribui para seu aprendizado e auxilia no desenvolvimento de habilidades e competências, tais como: capacidade de comunicação, trabalho em equipe e aptidão para refletir sobre situações reais, podendo os mesmos interligarem as atividades práticas com a teoria estudada, o que auxiliará na análise crítica.

A principal limitação encontrada nesta pesquisa refere-se à amostra não probabilística, já que os membros da população selecionados foram exclusivamente os alunos que se dispuseram a responder o questionário. Como sugestão para pesquisas futuras, propõe-se a busca por um maior aprofundamento sobre o tema por meio do uso de métodos qualitativos que complementem esta pesquisa e possibilitem novas discussões sobre o tema.

\section{Referências}

ABRANTES, D.; MARIANO, S. R. H.; MAYER, V. F. Metodologia para desenvolvimento de estudos de caso. Brasil: SEBRAE, 2002. Disponível em: $<$ www.casosdesucesso.sebrae.com.br/artigo/Metodologia\%20de\%20estudo.pdf $>$. Acesso em: 20 jul. 2015.

AMBROSINI, V.; BOWMAN, C.; COLLIER, N. Using teaching case studies for management research. Strategic Organization, v. 8, n. 3, p. 206-229, 2010. Disponível em: http://journals.sagepub.com/doi/pdf/10.1177/1476127010374254. Acesso em: 20 de fev. 2016. DOI: https://doi.org/10.1177/1476127010374254

ANTONELli, R. A.; COLAUTO, R. D.; CUNHA, J. V. A. Expectativa e Satisfação dos Alunos de Ciências Contábeis Com Relação às Competências Docentes. REICE - Revista Iberoamericana sobre Qualidade Eficácia e Mudança em Educação. v. 10, n. 01, p. 74-91, 2012. Disponível em: <http://www.rinace.net/reice/numeros/arts/vol10num1/art5.pdf $>$ Acesso em: 18 mai.2016.

ARAGÃO, C. V.; SANGO, M.C.A. O método do caso no ensino de administração pública: um exercício prático. Cadernos EBAPE/FGV, n. 77. Rio de Janeiro: Editora FGV, 1995.

ARAUJO, M. D. C., SANTANA, C. M. Análise das percepções e expectativas dos alunos de ciências contábeis na universidade de Brasília quanto ao perfil do professor e inserção no mercado de trabalho. Congresso USP de Contabilidade e Controladoria, 8, 2008. Anais... São Paulo: USP, 2008.

BORDENAVE, J. D.; PEREIRA, A. M. Estratégias de ensino-aprendizagem. Petrópolis, RJ: Vozes, 2006.

BRASIL. Resolução CNE/ CES no. 10, de 16 de dezembro de 2004. Institui as Diretrizes Nacionais Curriculares para o Curso de Graduação em Ciências Contábeis, bacharelado, e dá outras providências. In: CONSELHO NACIONAL DE EDUCAÇÃO - CÂMARA DE 
EDUDAÇÃO SUPERIOR. Legislação Republicana Brasileira. Brasília, 2004. Disponível em: $<$ http://portal.mec.gov.br/cne/arquivos/pdf/ rces10_04.pdf $>$. Acesso em: 26 jul. 2015.

BRUNER, R.; GUP, B. E.; NUNNALLY JR., B. H.; PETTIT, L. C. Teaching with cases to graduate and undergraduate students. Financial Practice and Education, Tampa, v. 9, n. 2, p. 138-146, 1999.

CAPES. Coordenação de Aperfeiçoamento de Pessoal de Nível Superior. 2016. Plataforma Sucupira. Disponível em:

$<$ https://sucupira.capes.gov.br/sucupira/public/consultas/coleta/programa/listaPrograma.jsf $>$. Acesso em: 21 jan. 2016.

CELERINO, S.; PEREIRA, W. F. C. Atributos e prática pedagógica do professor de contabilidade que possui êxito no ambiente universitário: visão dos acadêmicos. Revista Brasileira de Contabilidade, v. 37, n. 170, p. 64-77, 2008. Disponível em: $<$ http://rbc.cfc.org.br/index.php/rbc/article/view/793>. Acesso em: 27 mar. 2016.

COSTA. M. M; BARROSO, D. O método de casos no ensino da administração. Trabalho final da disciplina Técnicas de Ensino. Rio de Janeiro: EBAPE/FGV, 1992.

DE ASSIS, L. B. et al. Estudos de caso no ensino da Administração: o erro construtivo libertador como caminho para inserção da pedagogia crítica. Rev. Adm. Mackenzie - RAM, São Paulo, v. 14, n. 5, p. 44-73, 2013. Disponível em: $<$ http://editorarevistas.mackenzie.br/index.php/RAM/article/view/3997>. Acesso em: 9 jun. 2014. DOI: https://doi.org/10.1590/S1678-69712013000500003

FÁVERO, L. P; BELFIORE, P.; SILVA, F. L.; CHAN, B. L. Análise de dados: modelagem multivariada para tomada de decisões. Rio de Janeiro: Elsevier, 2009.

GIL, A. C.; LICHT, R. H. G.; OLIVA, E. C. A utilização do estudo de caso na pesquisa em administração. Revista Base (Administração e Contabilidade) da UNISINOS, São Leopoldo, v. 2, n. 1, p. 47-56, 2005. Disponível em: $<$ http://www.redalyc.org/articulo.oa?id=337228628005>. Acesso em: 15 jul. 2014.

GIL, A. C. Métodos e técnicas de pesquisa social. 5.ed. São Paulo: Atlas, 1999.

GIL, A.C. Elaboração de Casos para o Ensino da Administração. Revista Contemporânea de Economia e Gestão. v. 2, n. 2, p. 07-16, jul/dez. 2004. Disponível em: $<$ http://www.contextus.ufc.br/index.php/contextus/article/view/36/5> >. Acesso em: 29 jun. 2015 .

GRAHAM, A. Como escrever e usar estudos de caso para ensino e aprendizagem no setor público. Brasília: ENAP, 2010.

HAIR JR, J. F.; BLACK, W. C.; BABIN, B. J.; ANDERSON, R. E.; TATHAM, R. L. Análise multivariada de dados. Porto Alegre: Bookman, 2005.

HAMMOND, J. S. Learning by the case method. Boston: HBS Publishing, 2002. 
IKEDA, A. A.; VELUDO-DE-OLIVEIRA, T. M.; CAMPOMAR, M. C. A tipologia do método do caso em administração: usos e aplicações. Organizações \& Sociedade, v. 12, n. 34, p. 141-159, 2005. Disponível em < ttp://www.portalseer.ufba.br/index.php/revistaoes/article/view/10796> Acesso em: 4 jun. 2015. DOI: http://dx.doi.org/10.1590/S1984-92302005000300009

IKEDA, A. A.; VELUDO-DE-OLIVEIRA, T. M.; CAMPOMAR, M. C. O caso como estratégia de ensino na área de Administração. Revista de Administração da Universidade de São Paulo, São Paulo, v. 41, n. 2, p. 147-157, 2006. Disponível em: $<$ http://www.rausp.usp.br/busca/artigo.asp?num_artigo=1189>. Acesso em: 4 jun. 2015.

IKEDA, A. A.; VELUDO-DE-OLIVEIRA, T. M.; CAMPOMAR, M. C. O Método do Caso no Ensino de Marketing. RAC-Eletrônica, v. 1, n. 3, art. 4, p. 52-68, 2007. Disponível em: $<$ http://www.spell.org.br/documentos/download/30811 >. Acesso em: 01 Ago. 2015.

INEP - Instituto Nacional de Estudos e Pesquisas Educacionais. Diretoria de Informações e Estatísticas Educacionais (INEP/SEEC). Censo do Ensino Superior, 2017. Disponível $\mathrm{em}:<\mathrm{http} / /$ download.inep.gov.br/educacao_superior/censo_superior/apresentacao/2017/aprese ntacao_censo_educacao_superior.pdf >. Acesso em: 15 mar. 2018.

KNECHEL, W. R. Using the case method in accounting instruction. Issues in Accounting Education, Sarasota, v. 7, n. 2, p. 205-217, 1992.

LAFFIN, M. De Contador a Professor: a trajetória da docência no ensino superior de contabilidade. Florianópolis: Imprensa Universitária, 2002 Disponível em: http://repositorio.ufsc.br/xmlui/handle/123456789/82933> Acesso em: 20 jul. 2015.

LOURENÇO, C. D. S.; MAGALHÃES, T. F. A sala de aula e as empresas: Análise da produção e da utilização de casos para ensino em Administração. Administração: ensino e pesquisa, Rio de Janeiro, RJ. v. 15, n. 1, p. 11-42, jan/fev/mar 2014. DOI: http://dx.doi.org/10.13058/raep.2014.v15n1.41

MACHADO, A. G. C.; CALLADO, A. A. C. Precauções na adoção do método de estudo de caso para o ensino de administração sob uma perspectiva epistemológica. Cadernos EBAPE.BR, Rio de Janeiro, Número Especial, p. 1-10, 2008. Disponível em: $<$ http://bibliotecadigital.fgv.br/ojs/index.php/cadernosebape/article/viewFile/5433/4167>.

Acesso em: 4 jun. 2014.

MACY,G.;NEAL,J.C. The dialogic case method: building a microword in classroom. Organization Development Journal, Chesterland, v. 20, n. 3, p. 3142, 2002.

MARTINS, G. de A. Estudo de caso: uma estratégia de pesquisa. São Paulo: Atlas, 2006.

MARTINS, G. de A.; THEÓPHILO, C. R. Metodologia da investigação científica para ciências sociais aplicadas. São Paulo: Atlas, 2007.

MENEZES, M. A. A. Do método do caso ao case: a trajetória de uma ferramenta pedagógica. Educação e Pesquisa. São Paulo, v. 35, n.1, p. 129-143, jan./abr. 2009. Disponível em: < http://www.scielo.br/pdf/ep/v35n1/a09v35n1.pdf > Acesso em: 14 jun. 2015. http://dx.doi.org/10.1590/S1517-97022009000100009 
PEREIRA, C.M.; LEAL, E. A. Contribuição do método do estudo de caso no processo de ensino e aprendizagem da disciplina de análise de custos do curso de ciências contábeis. In: SemeAd, 18, 2015. Anais... São Paulo: FEA-USP, 2015.

PILETTI, C. Didática geral. São Paulo: Ática, 2004.

REES, W. D.; PORTER, C. The use of case studies in management training and development. Industrial and Commercial Training, Guilsborough, v.34, n.1, p.5-8, 2002.Part 1. Disponível em < https://www.emeraldinsight.com/doi/abs/10.1108/00197850210414026> Acesso em: 15 jul. 2015. DOI: http://dx.doi.org/10.1108/00197850210414026

RICHARDSON, R. J. Métodos e técnicas de pesquisa social. 5. ed. São Paulo: Atlas, 1999.

ROESCH, S. M. A. Notas para a construção de casos para ensino. Revista de Administração Contemporânea, v. 11, p. 1-10, 2007a. DOI: http://dx.doi.org/10.1590/S14156555200700020001

ROESCH, S. M. A. Como escrever casos para o ensino de administração. São Paulo: Atlas, $2007 b$.

SHUELL, T. J. Cognitive conceptions of learning. Review of Educational Research, v.56, p. 411-436, 1986. Disponível em <https://web-

basededucationalmaterials.wikispaces.com/file/view/cognitive+conceptions + of + learning. PDF> Acesso em 15 Mar. 2018

SILVA, E. R.; CASTILHO, D. Método do caso aplicado ao ensino da Administração: uma alternativa possível. Revista Eletrônica da Faculdade Metodista Granbery, Juiz de Fora, n. 10, p. 1-18, 2011. Disponível em: <http://re.granbery.edu.br/artigos/NDIw.pdf>. Acesso em: 15 jul. 2015.

SILVA, R. R.; BENEGAS, A. A. O uso do estudo do caso como método de ensino na graduação. Economia \& Pesquisa, v. 12, n. 12, p. 9-31, 2010. Disponível em: $<$ http://www.feata.edu.br/downloads/revistas/economiaepesquisa/v12_artigo01_uso.pdf $>$.

Acesso em: 14 fev. 2015. DOI: https://doi.org/10.6005/2179-6009.2010v12p9

VASCONCELOS, A. F.; CAVALCANTE, P. R. N.; MONTE, P. A. Fatores que influenciam as competências em docentes de Ciências Contábeis. Veredas FAVIP (Online), v. 5, p. 86$101,2012$.

VASCONCELOS, Y. L. et al. Método de caso e estudo de caso: usos no exercício da docência em contabilidade de custos. Custo e @gronegócio, Recife, v. 9, n. 4, p. 2-18, 2013. Disponível $\mathrm{em}$ : <http://www.custoseagronegocioonline.com.br/numero4v9/Metodo.pdf $>$. Acesso em: 4 jun. 2014.

VERGARA, S. C. Projetos e relatórios de pesquisa em administração. 5. ed. São Paulo: Atlas, 2004.

WEBER, M. M.; KIRK, D. J. Teaching teachers to teach cases: it's not what you know, it's what you ask. Marketing Education Review, Columbia, v. 10, n. 2, p. 59-67, 2000. 
WEIL, S.; OYELERE, P.; YEOH, J.; FIRER, C. A study of students' perceptions of the usefulness of case studies for the development of finance and accounting-related skills and knowledge. Accounting Education, v. 10, n. 2, p.123-146, 2001. Disponível em: < https://www.tandfonline.com/doi/abs/10.1080/09639280110081642>. Acesso em: 4 jun. 2015. DOI: $10.1080 / 09639280110081642$

Uma versão prévia (preprint) deste trabalho foi apresentado e publicado nos anais do evento Semead (2016). 